\title{
An Analysis of Counselling Areas Related to Peer Counselling Services among Public Secondary School Students in Meru South District, Kenya
}

\author{
Conny Kaari Kaaria \\ Dr. Veronica K. Nyaga \\ Monicah Buyatsi Oundo \\ Mary Murangi Mureithi \\ Department of Education, Chuka University \\ P. O. Box 109 - 60400, Chuka. Kenya \\ E-mail: connykaari@yahoo.com
}

Doi:10.5901/mjss.2014.v5n6p211

\begin{abstract}
Peer counsellors in secondary schools are pivotal in helping students to cope with life's challenges emanating from current socioeconomic changes, technological development and educational demands among other factors. Thus, the purpose of this study was to examine counselling areas related to peer counselling services among secondary school students in Meru South District, Kenya with the view of enhancing peer counsellors' intervention knowledge and skills through educational programmes and facilitation workshops. The study employed the descriptive survey research design and the target population was 600 peer counsellors from the 30 secondary schools in the District. The study employed two sets of questionnaires for data collection. The findings indicated that peer counsellors frequently dealt with issues of low academic achievement, financial hardships, stress, daydreaming, peer pressure, theft and negative attitudes towards certain teachers and subjects. Hence, it was recommended that training programmes emphasize counselling skill and knowledge in the areas.
\end{abstract}

Keywords: Counselling; Peer counsellors; Counselling areas;

\section{Introduction}

The contemporary society is laden with challenges emerging from the social setup, family background, political instability, economic constrains and religious affiliations. Essentially, these challenges including drug and substance abuse, violence, divorce and cults adversely impact on the various institutions of learning ranging from primary schools to universities (Arudo, 2008) thus, necessitating some form of intervention. Fortunately, the Kenyan government has instituted guidance and counselling services in all institutions of learning to enhance students' social, personal, career and academic competencies. However, most secondary school counsellors in Kenya have high teaching work loads and limited time to adequately serve all the student clients in schools (Nyamwaka, Ondima, Nyamwange, Ombaba \& Magaki, 2013). Therefore, peer counselling services have been established in schools to assist school counsellors in handling a variety of counselling needs among students (Marangu, Bururia \& Njonge, 2012). Apparently, the peer counselling relationship which exudes warmth, understanding and similarity of experiences plays a unique role in behaviour change among students because the clients are likely to model after the peer counselors by readily adopting their supposedly effective coping skills and problem solving strategies (Sisca, 1992). However, although peer counsellors may seem influential and competent to deal with a wide range of students' difficulties, continuous counselling knowledge and skill acquisition should not be underestimated. Besides, there are some aspects of students' counselling issues that should be referred directly to the teacher counsellor or any other appropriate practitioner depending on the nature and magnitude of the challenge (Cowie \& Sharp, 1996). Still, in cases where the peer counsellors have to deal with countless areas of counselling, it may affect their effectiveness in promoting behaviour change among the secondary school students. Therefore, it is crucial that the expansiveness of the peer counsellors' area of operation in terms of the types of issues presented by the students for counselling be established in order to equip the peer counsellors with appropriate knowledge, skills and methods for counselling the students. Hence, is is against this background that this study sought to 
carry out an analysis of counselling areas related to peer counselling services among public secondary school students in Meru South District in Kenya.

\section{Objectives of the study}

The main objective of this study was to analyze counselling areas related to peer counselling services among secondary school students.

\section{Research methodology}

This study employed the descriptive survey research design. The population of the study was 600 peer counsellors from 30 secondary schools with operational peer counselling departments in Meru South District. A sample size of 255 peer counsellors from 15 secondary schools was selected by use of purposive sampling and simple random sampling techniques. Data for the study were collected by use of questionnaires which generated information on demographic details of the respondents and areas of counselling namely: social, family, academic and psychological domains. A permit to collect data during the months of May and June 2012 was granted by the National Council of Science and Technology. Thereafter, a pilot study was conducted in order to improve on the reliability of the questionnaires. The pilot study generated a reliability coefficient of 0.82 for the teacher counselors and 0.78 for the peer counsellors, using the Chronbanch's Alpha Coefficient. The research instruments were then administered after obtaining permission from the school administration and informed consent from the perticipants who were assured of confidentiality before voluntarily completing the questionnaires. The obtained data were coded and entered into the computer for analysis by use of SPSS version 17.0 where frequency counts and percentages were utilized in the data analysis whose results were presented on tables.

\section{Findings and discussion}

This section contains an integration of the findings and discussions of this study. The section is divided into two main headings: the demographic characteristics of the respondents and the counselling areas. In addition, the counselling areas are subdivided into: social, family, academic and psychological domains whose issues presented for intervention by the peer counsellors are indicated.

\subsection{Demographic details of the respondents}

Data partaining demographic characteristics of the respondents were meant to generate information concerning the nature of the study participants. The findings indicated that majority of the peer counselors representing $48.4 \%$ were picked by teachers to offer counselling services to the students while only $4 \%$ of the respondents applied to offer the counselling services. Concerning length of service as peer counselors, it appears that the highest proportion of the respondents comprising $60.6 \%$ had served for one to two years in comparison to $1.3 \%$ of the peer counsellors who had offered services for over four years. This bears the implication that a large number of peer counselors may be lacking experience in terms of the duration of counseling. Therefore, it can be inferred that the lack of adequqte experience may pose a challenge regarding the quality of peer counselling services in secondary schools. Thus, continuous peer counsellor education and facilitation is paramount in order to mediate the inadequate exposure.

\subsection{Areas of Counselling}

This section presents the various issues secondary school peer counsellors contend with while interacting with student clients. These issues have been categorized into social, family, academic and psychological domains.

\subsubsection{Social Issues}

Information on social issues presented to peer counsellors by secondary school students is represented on table 1 . The respondents were meant to indicate the type of issues which were commonly presented for handling and the responses were valued on a 5 level likert scale ranging from Most Frequently (MF), Frequently (F), Sometimes (S), Rarely (R) and Never (N). 
Table 1. Social Issues

\begin{tabular}{|l|c|c|c|c|c|}
\hline \multicolumn{1}{|c|}{ Social Issues } & MF & $\mathbf{F}$ & $\mathbf{S}$ & $\mathbf{R}$ & $\mathbf{N}$ \\
& $(\%)$ & $(\%)$ & $(\%)$ & $\begin{array}{c}\text { N } \\
(\%)\end{array}$ & $(\%)$ \\
\hline Disturbances from opposite sex (Boy/Girl relationship) & 17.6 & 19.8 & 35.2 & 18.9 & 8.4 \\
\hline Fighting in school & 1.7 & 5.2 & 21.6 & 40.7 & 30.7 \\
\hline Stealing & 13.5 & 20.4 & 27.8 & 19.1 & 19.1 \\
\hline Rejection by other students & 7.1 & 10.7 & 36 & 28 & 18.2 \\
\hline Bullying and harassment & 1.8 & 8.3 & 26.3 & 25.4 & 38.2 \\
\hline Cheating in exams & 4.3 & 6.5 & 29 & 24.2 & 35.9 \\
\hline Destruction of personal/school property & 4 & 6.2 & 20 & 27.6 & 42.2 \\
\hline Negative peer influence & 17.8 & 25.8 & 28 & 16.9 & 11.6 \\
\hline Smoking, drug abuse and alcohol consumption & 4.7 & 8.2 & 15.5 & 19.3 & 52.4 \\
\hline
\end{tabular}

Observations on Table 1 indicate that different social issues were handled by peer counsellors but their frequencies varied with the type of challenge. It appears that the social issues frequently handled by the peer counsellors included disturbances from the opposite sex, stealing, and negative peer influence which implies that more weight may be required on these issues when preparing educational and skill training materials for the peer counsellors. Consenting to these views, Nyutu and Gysbers (2008) assert that secondary school students require guidance and counselling in human relationships and social issues. Further, Slavin (2005) suggests that peer counsellors have the responsibility of helping students resolve conflicts including a variety of personal and interpersonal problems ranging from insults and perceptions of unfairness among students, stealing and physical aggression. Generally, due to negative perceptions of the school counselling programme (Nyamwaka, Ondima, Nyamwange, Ombaba \& Magaki, 2013), secondary school students may feel reluctant to disclose such social issues to the school counsellor for fear of victimization and punishment hence, the need to equip the peer counsellors with the necessary skills. Basically, the other social issues that were noted by peer counsellors as being less frequent such as smoking, drug abuse, destruction of school property, bullying, harassment and fighting were most likely to have been directly addressed by the school administration.

\subsubsection{Family Issues}

Information on table 2 shows the peer counsellors responses regarding to some of the counselling issues emanating from the family. The responses were valued on a 5 level likert scale ranging from Most Frequently (MF), Frequently (F), Sometimes (S), Rarely (R) and Never (N).

Table 2. Family Issues

\begin{tabular}{|l|c|c|c|c|c|}
\hline \multicolumn{1}{|c|}{ Issues } & $\begin{array}{c}\text { MF } \\
(\%)\end{array}$ & $\begin{array}{c}\text { F } \\
(\%)\end{array}$ & $\begin{array}{c}\text { S } \\
(\%)\end{array}$ & $\begin{array}{c}\mathbf{R} \\
(\%)\end{array}$ & $\begin{array}{c}\text { N } \\
(\%)\end{array}$ \\
\hline Beaten by parents & 1.8 & 4 & 19.5 & 31.9 & 42.9 \\
\hline Parents refusing to provide personal effects & 4 & 7.9 & 29.1 & 28.2 & 30.8 \\
\hline Drunkenness of parents & 3.5 & 13.2 & 25 & 17.1 & 41.2 \\
\hline Conflicts between parents & 7.9 & 11 & 29.1 & 23.3 & 28.6 \\
\hline Conflicts among siblings & 6 & 10.1 & 27.1 & 24.8 & 32.1 \\
\hline Financial hardships & 14.2 & 19.1 & 38.2 & 16 & 12.4 \\
\hline Parents dead & 5 & 6.8 & 23.1 & 29 & 36.2 \\
\hline Mistreated by step-parents or guardians & 8 & 10.7 & 20.1 & 23.7 & 37.5 \\
\hline Loss of a family member or friend & 4 & 7.1 & 29.3 & 36.4 & 23.1 \\
\hline
\end{tabular}

As presented on Table 2, family issues requiring peer counselling services that were rated as most frequent or just frequent among students included financial hardships followed by drunkenness of parents then mistreatment by step parents or guardians and conflict between parents. In agreemet with the findings on family financial hardships, Arudo (2012) purports that students are most likely to skip classes or even drop out of school as a result of lack of school fees. Further, family conflicts such as alcoholism, parental conflict and child abuse are hypothesized to significantly disturb students. According to Santrock (2001) problematic parent child relationships that are coercive and hostile lead to the development of an antisocial disposition in the child which may contribute in academic failure and rejection by 
classmates. Therefore, it is important that peer counselors be able to identify and assist the students in coping or dealing with the family issues. Nevertheless, it is pleasant that students are able to speak to peer counsellors about disturbing family issues because internalizing problems over which one has no direct control may lead to stress, declining academic performance, psychosomatic complaints and depression. However, cases involving physical assult and negligence such as being beaten by parents and parents refusing to provide personal effects respectively should be referred for necessary action because they interfere with the childrens' rights.

\subsubsection{Academic Issues}

Information on Table 3 presents some of the issues related to academic performance which the peer counsellors are likely to offer services in. The responses were valued on a 5 level likert scale ranging from Most Frequently (MF), Frequently (F), Sometimes (S), Rarely (R) and Never (N).

Table 3. Academic Issues

\begin{tabular}{|l|c|c|c|c|c|}
\hline \multicolumn{1}{|c|}{ Academic Issues } & MF & F & S & R & $\begin{array}{c}\text { N } \\
(\%)\end{array}$ \\
\hline Poor performance in class & 25.5 & 23.4 & 34.6 & 10.8 & 5.6 \\
\hline Deterioration of performance & 16.2 & 22.1 & 41 & 15.8 & 5 \\
\hline Difficult in learning certain subjects & 22.6 & 33.5 & 29.6 & 12.6 & 1.7 \\
\hline Bad study habits & 11.4 & 28.1 & 35.5 & 16.2 & 8.8 \\
\hline Low concentration in class & 14.8 & 26.6 & 38 & 13.1 & 7.4 \\
\hline Failure to complete assignments on time & 10.9 & 16.1 & 34.8 & 27 & 11.3 \\
\hline Dislike of certain teachers & 19.1 & 21.7 & 23 & 18.7 & 17.4 \\
\hline Dislike of certain subjects & 23.4 & 24.2 & 28.1 & 16.9 & 7.4 \\
\hline
\end{tabular}

As indicated on Table 3, peer counsellors generally dealt with a variety of academic issues among students. Particularly, secondary school students had academic concerns about performance, study habits, concentration, assignments, subjects and teachers; which were directed at peer counsellors. Retrospectively, the high frequency at which peer counsellors encounter academic counselling issues from students may explain why Marangu, Bururia and Njonge (2012) advice that selection of peer counsellors be based on academic achievement. This is important because peer counsellors can best impact on students' academic performance though modeling excellent achievement and academic orientation. Besides, Steinberg (2002) asserts that peers are a significant influence on adolescents' day-to-day school behaviours and feelings including how they value school, how much effort they devote to their studies and how well they perform in class. Therefore, proper skills in peer academic group discussions such as time management, leadership, organizational skills, study habits and test skills should be inculcated among peer counsellors.

\subsubsection{Psychological Issues}

Information on the psychological related issues likely to be presented to the peer counsellors by the students is shown on Table 4. The respondents were meant to indicate the type of counselling issues which were commonly presented for handling and the responses were valued on a 5 level likert scale ranging from Most Frequently (MF), Frequently (F), Sometimes (S), Rarely (R) and Never (N).

Table 4. Psychological Related Issues

\begin{tabular}{|l|c|c|c|c|c|}
\hline \multicolumn{1}{|c|}{ Statements } & $\begin{array}{c}\text { MF } \\
(\%)\end{array}$ & $\begin{array}{c}\mathbf{F} \\
(\%)\end{array}$ & $\begin{array}{c}\text { S } \\
(\%)\end{array}$ & $\begin{array}{c}\mathbf{R} \\
(\%)\end{array}$ & $\begin{array}{c}\mathbf{N} \\
(\%)\end{array}$ \\
\hline Dissatisfied with self image/looks & 4.9 & 13.3 & 24.3 & 23.9 & 33.6 \\
\hline Stress & 22.5 & 27.3 & 32.5 & 11.7 & 6.1 \\
\hline Lack of sleep at night & 3.5 & 7.9 & 23.2 & 32 & 33.3 \\
\hline Sleeping in class & 24.6 & 22.8 & 29.9 & 14.3 & 8.5 \\
\hline Day dreaming/absent minded in class & 17.4 & 17.4 & 33.5 & 20.5 & 11.2 \\
\hline Feeling unaccepted by friends & 11.4 & 15.8 & 28.5 & 27.6 & 16.7 \\
\hline Disturbed about physical and biological development & 7.2 & 9.4 & 30 & 22.4 & 30.9 \\
\hline
\end{tabular}


Information on Table 4 reveals that peer counsellors were most frequently confroted with psychological issues regarding students' stress, sleeping in class, day dreaming and feelings of peer rejection. Although other issues such as negative self concept, insomnia and developmental concerns were relatively less frequent, their influence on students' life may be momentous. Therefore, special training is necessary to enable peer counsellors to form counselling relationships that foster clients' self knowledge, self esteem, self concept and self acceptance in order to apprehend potential psychological problems and mental disorders (Arudo, 2012). It is also important to empower peer counsellors with knowledge and skills of assessing the underlying causes of students' psychological issues, identifying appropriate cases for referral and positively influencing reluctant clients to accept specialized counselling or treatment.

\section{Recommendations}

To facilitate and improve peer counselling services in secondary schools, the following recommendations were made based on the findings of this study:

i. There is need to equip peer counsellors with appropriate counseling knowledge and skills to ensure that they are capable of handling the diverse issues of counseling presented by the students. This can be accomplished through training and refresher courses to the already trained peer counsellors.

ii. Peer counsellors should be encouraged to refer the difficult cases to qualified persons in the school such as the teacher counsellor so that the student/client is fully assisted. This is because some of the issues may be beyond the peer counsellor's ability.

iii. Parents should be encouraged to meet all family financial needs either by seeking side ventures, improving on budgeting skills, minimizing on luxuries, family planning or seeking bursaries and scholarships for the childrens' education. School counsellors should enlighten parents and guardians regarding the effect of family conflicts and dysfunctions on students' personal, social, psychological and academic life.

iv. School administrators should provide an academic environment that ensures all students attain personal academic potentials. Strategies should also be put in place to curb stealing among students. The classrooms should be built using concrete roofs to enhance favourable learning temperatures thus stop students from dosing during lessons.

\section{References}

Arudo, T. O. (2008). Peer Counselling among Selected Kenyan Secondary Schools. Retrieved on $8^{\text {th }}$ December 2013 from http://www.kapc.or.ke/downloads/Arudo,\%252

Cowie, H. \& Sharp, S. [eds.] (1996). Peer Counselling in Schools. London: David Fervulton Publishers

Maiyo, J. K. \& Owiye, J. (2009). The Role of Guidance and Counselling in Secondary Schools in Kenya. Prospects and Challenges. Problema of Education in the 21st Centuary. 15: $99-108$

Marangu, P. C.; Bururia, D. N. \& Njonge, T. (2012).Challenges Faced By Peer Cousellors in their Effort to Effect Behaviour Change in Secondary Schools in Maara District, Kenya. American International Journal of Conteporary Research. 2(11): $79-85$.

Nyamwaka, E. O.; Ondima, P. C.; Nyamwaka, C.; Ombaba, S. \& Magaki, E. K. (2013). Assessment of Implimentation Levels of Guidance and Counselling Programme in Kenyan secondary Schools: A Case of Sotik District, Bomet County, Kenya. Journal of Education and Practice. 4(3) 178 - 186.

Nyutu, P. N. \& Gysbers, N. C. (2008). Assessing the Counselling Needs of High School students in Kenya. International Journal for Education and Vocational Guidance. 8(2): $83-94$

Santrock, J. W. (2001). Educational Psychology. First Edition. Boston, Mc Graw-Hill Publishing Company.

Sisco, P. (1992). Peer Counselling: An Overview. Retrieved on $7^{\text {th }}$ December 2013 from http://www.independentliving.org Itoolsforpower/tools22.html

Slavin, R.E. (2005). Educational Psychology: Theory and Practice. Seventh Edition. Printed in United States of America

Steinberg, L. (2002). Adolescence. Sixth Edition. New York: Temple University Mc Graw-Hill Companies. 
